\title{
Computational modelling folate metabolism and DNA methylation: implications for understanding health and ageing
}

\author{
Mark T. Mc Auley, Kathleen M. Mooney and J. Enrique Salcedo-Sora
}

Corresponding author. Mark Mc Auley, Department of Chemical Engineering, Thornton Science Park, University of Chester, Chester CH2 4NU, UK. Tel.: +44(0124) 513927; E-mail: m.mcauley@chester.ac.uk

\begin{abstract}
Dietary folates have a key role to play in health, as deficiencies in the intake of these B vitamins have been implicated in a wide variety of clinical conditions. The reason for this is folates function as single carbon donors in the synthesis of methionine and nucleotides. Moreover, folates have a vital role to play in the epigenetics of mammalian cells by supplying methyl groups for DNA methylation reactions. Intriguingly, a growing body of experimental evidence suggests that DNA methylation status could be a central modulator of the ageing process. This has important health implications because the methylation status of the human genome could be used to infer age-related disease risk. Thus, it is imperative we further our understanding of the processes which underpin DNA methylation and how these intersect with folate metabolism and ageing. The biochemical and molecular mechanisms, which underpin these processes, are complex. However, computational modelling offers an ideal framework for handling this complexity. A number of computational models have been assembled over the years, but to date, no model has represented the full scope of the interaction between the folate cycle and the reactions, which governs the DNA methylation cycle. In this review, we will discuss several of the models, which have been developed to represent these systems. In addition, we will present a rationale for developing a combined model of folate metabolism and the DNA methylation cycle.
\end{abstract}

Key words: folate metabolism; computational model; DNA methylation; ageing; stochastic model

\section{Introduction}

The term 'folate' (vitamin B9) is used to denote a group of compounds that possess the same vitamin activity and includes natural folates as well as the pharmacological compounds folic acid and folinic acid [1]. The dietary importance of folate cannot be overstated. This is emphasized by the wide range of clinical disorders, which correlate with low folate status [2-4]. In addition, polymorphisms in genes coding for folate-dependent enzymes [5, 6] are associated with several cancers (cervical, bronchial, colon and breast) [7-10], Alzheimer's disease [11], Down syndrome [12], unexplained recurrent early pregnancy loss and pre-eclampsia [13]. These associations are unsurprising when one considers that folates are involved in a ubiquitous array of cellular processes. For instance, folates are involved in the synthesis of nucleotides from purine precursors, participate indirectly in the synthesis of transfer RNA and function as single carbon donors during the re-methylation of homocysteine

Mark Mc Auley is a Computational Systems Biologist and Senior Lecturer of Chemical Engineering in the Faculty of Science and Engineering, University of Chester, UK. His research interests are computational modelling of nutrient-based systems and their interaction with ageing, specifically, folate and lipid metabolism.

Kathleen Mooney is a Nutritionist who works as a Senior Lecturer in Nutrition at Edge Hill University, UK. Her interest is the role of B vitamins in maintaining health.

Enrique Salcedo-Sora has a Medical Degree and a Master of Science/PhD in Biochemistry. Currently, he works as a Lecturer in Medical Biochemistry in the School of Health Sciences at Liverpool Hope University, UK. He is also an Honorary Research Fellow at the Liverpool School of Tropical Medicine, UK. He is interested in folate metabolism in both eukaryotic and prokaryotic organisms and how perturbations to folate metabolism can be used to help treat diseases such as malaria.

Submitted: 15 July 2016; Received (in revised form): 17 October 2016

(c) The Author 2016. Published by Oxford University Press. All rights reserved. For Permissions, please email: journals.permissions@oup.com 
(Hcy) to methionine [14] (Figure 1). Folate-derived one-carbon units also play a central role in DNA methylation $[15,16]$. This epigenetic process involves methyl groups covalently bonding to $\mathrm{CpG}$ dinucleotides to establish tissue-specific methylation patterns. A CpG dinucleotide consists of a deoxycytidine followed by a deoxyguanidine, with the ' $p$ ' indicating the phosphate group between these nucleotides. Covalent bonding of methyl groups occurs at the carbon-5 position of a deoxycytidine to create a methylated CpG dyad $[11,12]$. Dynamic changes to methylation patterns are an important gestational phenomenon, which regulate gene expression during embryonic development [17]. However, during adult life, alterations to DNA methylation patterns can have significant implications for the onset of disease $[18,19]$. Specifically, advancing age is often accompanied by global hypomethylation [20-23] in conjunction with site-specific hypermethylation at the promoter region of a variety of genes [24-27]. Hypermethylation involves CpG islands ( $500-2000 \mathrm{bp}$ ) within the promoter becoming excessively methylated $[28,29]$, and often occurs with concomitant transcriptional silencing [30, 31]. Gene promoter hypermethylation is a feature of certain diseases, the most notable being cancer [25]. For instance, Wang et al. (2016) [32] recently found that DNA methylation changes during ageing were closely correlated to the occurrence of cancer. In addition to cancer, aberrant DNA methylation has an emerging role to play in many age-related diseases, including cardiovascular disease (CVD) [33], Alzheimer's disease [34] and osteoporosis/osteoarthritis [35]. Such findings consolidate the growing view that DNA methylation status and health span are inexorably entwined. Moreover, it has also been revealed that investigating changes to the methylation profile of the genome could help develop our understanding of ageing. This assertion is supported by the recent bioinformatics work of Horvath (2013) [36] who used publicly available methylation data sets to identify an 'epigenetic clock' underpinned by methylation changes in 353 CpGs. Intriguingly, Horvarth postulates that 'DNA methylation age' measures the cumulative effect of an epigenetic maintenance system. This finding indicates that a deeper mechanistic understanding of DNA methylation preservation could be pivotal to improving our overall understanding of ageing and health span.

To extend our understanding of DNA methylation and its bidirectional relationship with ageing, it is imperative we consider how subtle alterations to folate-mediated one carbon metabolism (FOCM) impact the regulatory processes that govern DNA methylation. Specifically, it is necessary to explore how such perturbations affect gene promoters, which are susceptible to hypermethylation. In addition, it is vital we consider how other factors associated with ageing impact this relationship. However, this is not a straightforward task, as both FOCM and the DNA methylation cycle are complex processes, which are underpinned by a large number of biochemical and molecular reactions (Figure 1). Many of these reactions are non-linear in nature and are influenced by a variety of other B vitamins/nutrients and enzymatic cofactors [37]. Ageing adds a further degree of complexity by altering the dynamics of the reactions. For example, age-dependent decreases in the expression levels/ activity of human methionine synthase (MS) and methylenetetrahydrofolate reductase (MTHFR) have been observed [38, 39]. Both enzymes are recognized as key regulators of FOCM, and expression/activity changes potentially affect their reaction kinetics. Similarly, the activity of human DNA methyltransferase 1 (Dnmt 1), a key enzyme involved in the addition of methyl groups to cytosine residues, has also been observed to decrease with age [40]. Moreover, ageing also affects the availability of cofactors such as vitamin B12 [41], which is central to FOCM, while oxidative stress, which is generally regarded as a key contributor to ageing, has been observed to effect both DNA methylation and FOCM [42, 43]. Furthermore, it is not uncommon that older people have diminished folate status as a result of a low dietary intake of the vitamin [44]. Thus, it is necessary to consider an array of factors when investigating the maintenance of DNA methylation. Fortunately, there is a growing appreciation that complex biological process can be studied in a holistic manner by adopting a systems biology approach [45]. Computational modelling resides at the centre of this paradigm shift, as it provides a framework for representing and exploring the dynamics of complex systems [46-50]. In this review, we discuss the role computational modelling has played in developing our understanding of FOCM and DNA methylation. In addition, we propose coupling FOCM and the DNA methylation cycle into one computational model, which could be used to further explore the dynamics of their relationship.

\section{Folate metabolism and the DNA methylation cycle}

FOCM is fundamentally important to DNA methylation. Various folates are the cofactors for the de novo synthesis of methyl groups from more oxidized one-carbon units, and the methyl groups on 5-methyltetrahydrofolate (5-MTFHF) are used to re-methylate Hcy to methionine and to regenerate tetrahydrofolate, the metabolically active form of folate. Methionine is a precursor of S-adenosylmethionine (SAM), which has a predominant role to play in the majority of biochemical methyl donation events, including that of DNA methylation. Post-replication, Dnmt1 uses SAM as a substrate to transfer methyl groups to the DNA molecule [51]; this produces S-adenosylhomocysteine (SAH). SAH is then converted to Hcy, permitting the continuation of the methylation cycle [52, 53] (Figure 1). In conjunction with Dnmt1, DNA methylation patterns are dynamically regulated by several other enzymes (Figure 1). As Dnmt1 preferentially acts on hemimethylated DNA and is potentially unable to methylate neo-synthesized DNA strands, this enzyme is generally regarded as solely a maintenance enzyme [54]. Thus, other enzymes are needed to perform de novo DNA methylation. Dnmt3a and Dnmt3b are widely regarded as the main enzymes responsible for this role [55, 56]. These methylation reactions are offset by active and passive demethylation. Passive demethylation occurs during replication, while active methylation can involve 10-11 translocation (TET) dioxygenases, which oxidize the methyl groups of cytosine [57]. TET dioxygenases are thought to function by oxidizing the methyl groups of cytosine. This process eventually culminates with the reintroduction of unmethylated cytosine in the DNA molecule [57]. Thus, it would appear that the steady-state levels of both site-specific and global DNA methylation patterns are maintained by an antagonistic balancing act between those activities responsible for maintenance/de novo methylation and those reactions responsible for passive/active demethylation. Moreover, methylation fidelity studies suggest that these processes are subject to inherent stochasticity. For example, Landan et al. (2012) [58] tracked the in vitro evolution of immortalized fibroblasts for $>300$ generations and found that changes in population-averaged methylation occur through a stochastic process. In addition, Shipony et al. (2014) [59] suggest the persistence nature of the somatic methylome is one factor that makes it increasingly vulnerable to noise with time. This is 


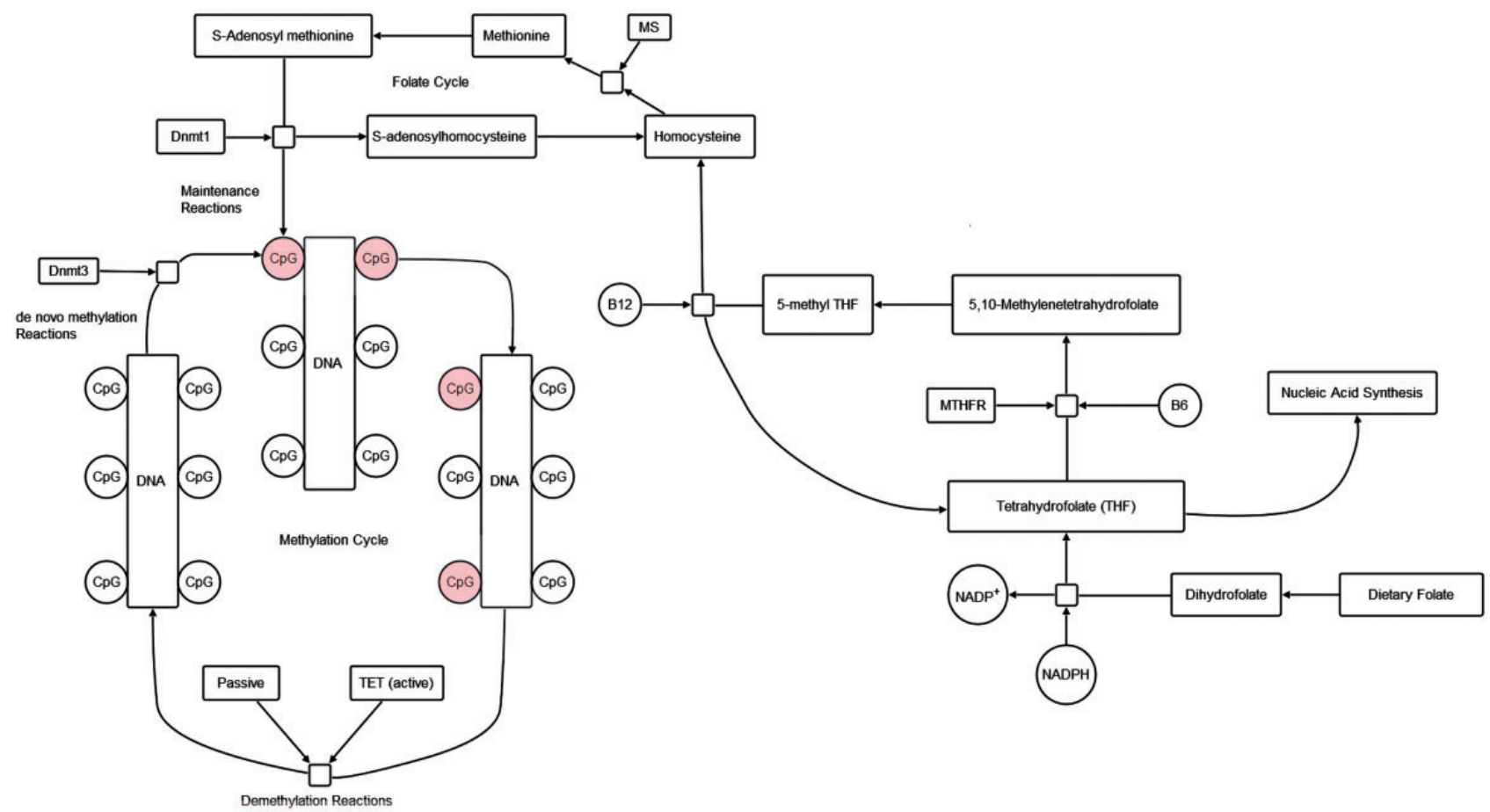

Figure 1. Folate metabolism and its intersection with DNA methylation: Ingested folates are the cofactors for the de novo synthesis of methyl groups. Methyl groups on 5-MTFHF are used to re-methylate homocysteine (Hcy) to methionine, with the aid of vitamin B12 and MS. This reaction regenerates tetrahydrofolate, the metabolically active form of folate. Methionine is a precursor of SAM, which has a predominant role to play in the majority of biochemical methyl donation events, including that of DNA methylation. Dnmt 1 is central to maintaining genomic methylation patterns, while Dnmt 3a and 3b are both involved in de novo methylation reactions. TET dioxygenases are actively involved in demethylating cytosine, while $\mathrm{CH}_{3}$ groups are also lost passively. Pink circles indicate methylated CpGs.

intriguing from the perspective of ageing, as it would appear that in young somatic cells, site-specific methylation density is characterized by low-level noise, which maintains average methylation density. Therefore, the persistent nature of the methylome and increased stochasticity with time could contribute to the formation of aberrant DNA methylation patterns, which are a hallmark of the ageing process in humans.

\section{Computational models of folate metabolism}

The models described in the next two sections are summarized in Tables 1 and 2, respectively. Models of FOCM have traditionally adopted a continuous deterministic approach, with the dynamics of the system being represented by ordinary differential equations (ODEs), which are underpinned by kinetic reactions [83]. In the main reaction, velocities are assumed to depend on the concentrations of the reaction substrates (the law of mass action [84]). Rate laws for more complex reaction laws are in general described by Michaelis-Menten kinetics [85] for one, two or three substrates assuming a random-order mechanism. The following mathematical expressions taken from the recent model by Salcedo-Sora and Mc Auley (2016) [67] encapsulate the different Michaelis-Menten-based functional forms as used for one, two and three substrates in these types of kinetic models, where $\mathrm{V}$ is the velocity of the reaction, $\mathrm{V}_{\max }$, is the theoretical maximum velocity of the reaction, S1-S3 are substrates and $k_{\mathrm{m} 1}-k_{\mathrm{m} 3}$ are the substrate concentrations at which the reaction is half maximum velocity.

$$
\mathrm{V}=\frac{\mathrm{V}_{\max } *[\mathrm{~S}]}{k_{m}+[\mathrm{S}]}
$$

$$
\begin{gathered}
\mathrm{V}=\frac{\mathrm{V}_{\max } *\left[\mathrm{~S}_{1}\right]\left[\mathrm{S}_{2}\right]}{k_{m_{1}} k_{m_{2}}+k_{m_{1}}\left[\mathrm{~S}_{2}\right]+k_{m_{2}}\left[\mathrm{~S}_{1}\right]} \\
\mathrm{V}=\frac{\mathrm{V}_{\max } *\left[\mathrm{~S}_{1}\right]\left[\mathrm{S}_{2}\right]\left[\mathrm{S}_{3}\right]}{k_{m_{1}} k_{m_{2}} k_{m_{3}}+k_{m_{1}}\left(\left[\mathrm{~S}_{2}\right]+\left[\mathrm{S}_{3}\right]\right)+k_{m_{2}}\left(\left[\mathrm{~S}_{1}\right]+\left[\mathrm{S}_{3}\right]\right)+k_{m_{3}}\left(\left[\mathrm{~S}_{1}\right]+\left[\mathrm{S}_{2}\right]\right)+\left[\mathrm{S}_{1}\right]\left[\mathrm{S}_{2}\right]\left[\mathrm{S}_{3}\right]}
\end{gathered}
$$

The first mathematical model to adopt this kinetic approach to represent intracellular folate metabolism was developed in the 1970s and had a strong pharmacological theme [60]. It was used to simulate the actions of methotrexate on DNA synthesis. The next significant computational model of the folate cycle was developed by Nijhout et al. (2004) [61]. This model is underpinned by the enzyme kinetic data that characterize the reactions in Figure 1, and was assembled using the type of mathematical equations outlined above. As well as being the first detailed mathematical description of the folate cycle, model simulations were able to quantitatively reproduce the intracellular levels of the various folate metabolites, and the model was able to predict the effect of vitamin B12 deficiency. Building on this work, Reed et al. (2006) [62] used this model combined with models of methionine metabolism $[63,64]$ to investigate genetic polymorphisms in the folate pathway. Polymorphisms in MTHFR predicted that a reduction in MTHFR activity reduces concentrations of SAM and 5-MTHR, and DNA methylation, while slightly increasing SAH and Hcy concentrations and thymidine or purine synthesis. Decreased folate together with a simulated vitamin B12 deficiency resulted in decreased DNA methylation and purine and thymidine synthesis. This model was also used as a template to study the effect of intracellular folate deficiency and excess. The model 
4 | Mc Auley et al.

Table 1. A summary of the models of folate metabolism cited in the text

\begin{tabular}{|c|c|c|c|}
\hline Authors & Title & Model overview/predictions & Computational methods used \\
\hline Jackson and Harrap (1973) [60] & $\begin{array}{l}\text { Studies with a mathematical } \\
\text { model of folate metabolism }\end{array}$ & $\begin{array}{l}\text { Included the main reactions } \\
\text { involved in cellular folate me- } \\
\text { tabolism in mouse leukaemia } \\
\text { cells. Used to predict time course } \\
\text { changes in purine and thymidy- } \\
\text { late biosynthesis rates. }\end{array}$ & $\begin{array}{l}\text { A deterministic framework con- } \\
\text { sisting of a system of integrated } \\
\text { equations. Kinetic parameters } \\
\text { were determined from pre-exist- } \\
\text { ing experimental data. }\end{array}$ \\
\hline
\end{tabular}

Nijhout et al. (2004) [61] A mathematical model of the folate cycle: new insights into folate homeostasis

Reed et al. (2006) [62]

Neuhouser et al. (2011) [65]

Duncan et al. (2013) [66]

Salcedo-Sora and Mc Auley (2016) [67]
Mathematical modelling predicts the effect of folate deficiency and excess on cancer-related biomarkers

A mathematical model gives insights into nutritional and genetic aspects of folate-mediated one-carbon metabolism$$
\text { biomarkers }
$$

\section{A Population Model of Folate- Mediated One-Carbon Metabolism [66]}

A mathematical model of micro-
Folate cycle underpinned by enzyme kinetics. Used to explore the 'methyl trap hypothesis', the effects of methotrexate and sensitivities to variation in enzymatic parameters.

Model of FOCM. Predictions included the inverse association between Hcy and low folate levels, DNA methylation reaction rate is relatively insensitive to changes in folate pool size, folate concentrations become high, enzyme velocities diminish, mutations in MTHFR reduces SAM.

FOCM model used by this group.

Used to predict: the effect of a broad range of intracellular folate concentrations simulating variation in folate status on mechanisms relevant to carcinogenesis.

Compartmental body model folate metabolism.

Showed tissue and plasma folate is highly correlated, but liver and plasma folate much less so. Oxidative stress increases the plasma SAM/SAH ratio. bial folate biosynthesis and utilization: implications for antifolate development.
First model to be assembled of folate biosynthesis and utilization. The model suggested a particular small set of folate intermediates are specific targets that could complement current antifolates, and the model substantiates the case for a substrate cycle in the folinic acid biosynthesis reaction.
A deterministic ODE-based kinetic model constructed using the assumption that most reactions in the folate cycle are bimolecular.

Deterministic ODE model created by combining the model by Nijhout et al. (2004) and models of methionine metabolism $[63,64]$.

Deterministic model based on [62].

Models from [61, 62] were incorporated into liver and plasma compartment.

Coupled set of ODEs.

Random number used to generate a virtual population of 10000 individuals each with different folate metabolism.

Model constructed using Matlab.

Deterministic ODE model.

Folate pathway informed by the KEGG database (http://www.gen ome.jp/kegg/) and kinetic parameters were compiled from the enzyme database BRENDA (http:// www.brenda-enzymes.org/) suggested that the enzyme thymidylate synthesis is sensitive to changes in epithelial intracellular folate and increased significantly under conditions of high intracellular folate [65]. This framework was further extended by Duncan et al. (2013) [66] to hepatic and plasma folate turnover. It was applied to a population of virtual individuals and showed that tissue and plasma folates are highly correlated, but liver and plasma folates much less so. Moreover, this model showed that oxidative stress increases the plasma SAM/S-SAM/SAH ratio. The most recent ODE model of folate metabolism was developed by Salcedo-Sora and Mc Auley (2016) [67]. Our model is the first computational model of microbial folate biosynthesis and utilization. Using the model, we were able to identify specific targets within folate metabolism, which synergize with current antifolates. In addition, the results from our model support experimental findings that suggest the folinic acid substrate cycle is an important biochemical mechanism deployed during active cell growth, a key finding that emphasizes the utility of computational models for shedding light on this complex system.

\section{Computational models of the DNA methylation cycle}

A variety of approaches have been used to model various aspects of DNA methylation [68-74]. Our focus is the precise representation of the DNA methylation cycle. To this end, the DNA methylation cycle has been modelled explicitly by McGovern et al. (2012) [77]. The model centred on the activity of DNMTs, 


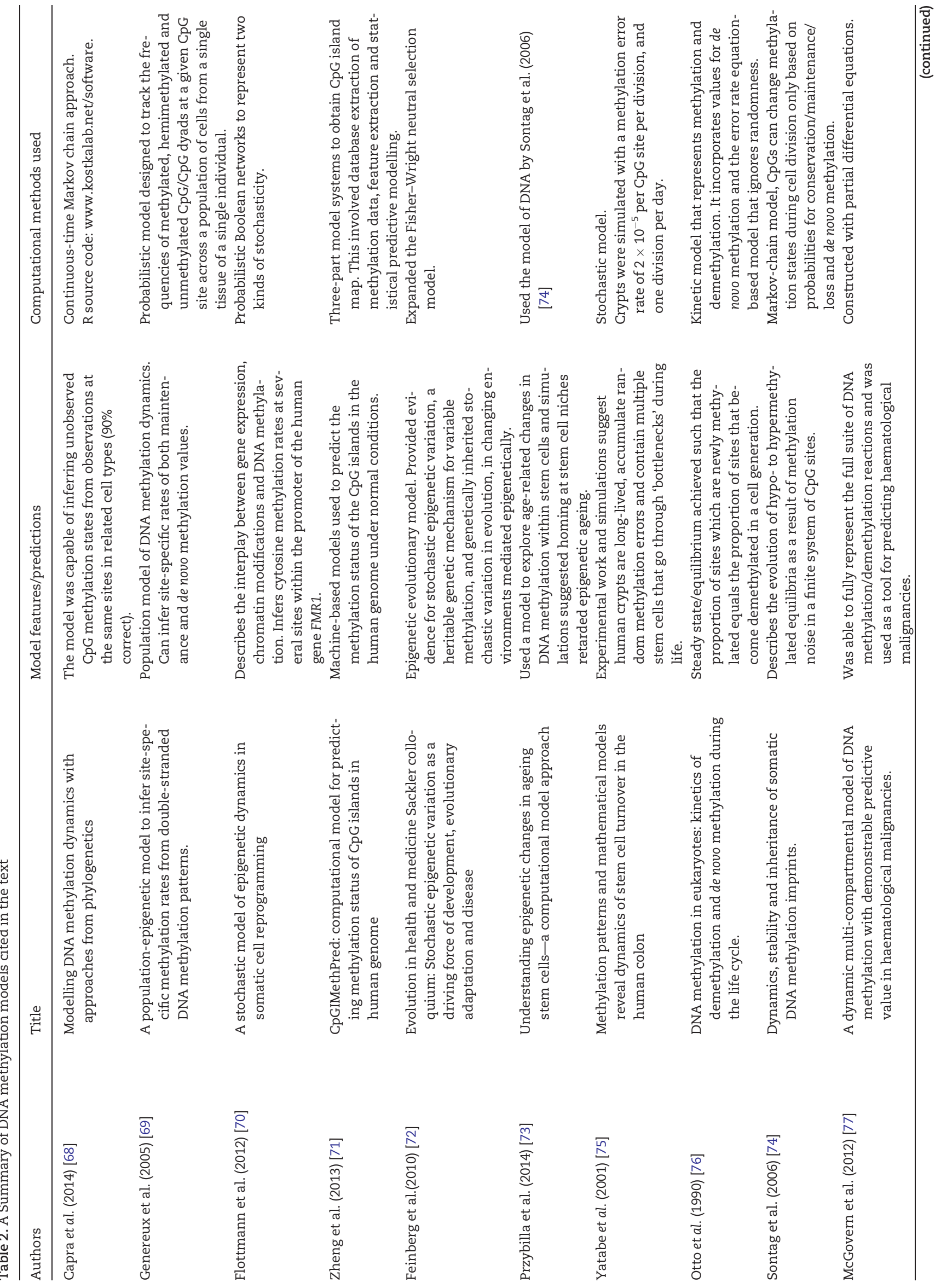


and partial differential equations were used to represent methylation reactions. It was used as a predictive tool for haematological malignancies. The model was able to predict the relative abundances of unmethylated, hemimethylated, fully methylated and hydroxymethylated CpG dyads in the DNA of cells with fully functional methylation and TET enzymes. In addition to this deterministic framework, stochastic models of the methylation cycle have also been used to study the methylation cycle. The goal has been to derive models that account for the noise associated with maintaining DNA methylation levels. For example, a reduced probabilistic mathematical representation of methylation dynamics (known as the standard/classical model) has been proposed by Pfeifer et al. (1990) [86], and further used by Riggs and Xiong (2004) [78]. This model is presented in Equations (4-7).

$$
\begin{aligned}
\frac{d M}{d t} & =E m * M+E d * U \\
\frac{d U}{d t} & =(1-E d) * U+(1-E m) * M \\
\mathbf{M}^{\wedge} & =\frac{M}{\text { Total }}=\frac{M}{(M+U)} \\
\mathbf{M}^{\wedge} & =\frac{E d}{(1+E d-E m)}
\end{aligned}
$$

To briefly explain the ODEs in Equations (4) and (5), and Equations (6) and (7), $M$ is a CPG site, $U$ is its unmethylated state, $E_{\mathrm{d}}$ is the efficiency of de novo methylation, $E_{\mathrm{m}}$ is the efficiency of maintenance methylation, $M$ is the number of methylated sites, $M^{\wedge}$ is the fraction of methylation, while Equation (7) represents the steady-state solution to ODEs 4 and 5 when $\mathrm{dM}^{\wedge}$ / $d t=0$. This model is underpinned by the idea that site-specific methylation levels are underscored by a stochastic process, where de novo and maintenance methylation activity are central. Recently, Jeltsch and Jurkowska (2014) [79] provided an intriguing theoretical extension to this concept. Jeltsch and Jurkowska propose a stochastic model, which also includes the rate of cell division together with passive and active demethylation; Equation (8). $\theta_{m}^{i}$ is the change in the fraction of methylation at any CpG site (i). This is determined by the difference between the rate of de novo DNA methylation $\left(r_{\text {met }}^{i}\right)$ and rates of loss of methylation by replication and active demethylation $\left(r_{\text {demeth }}^{\mathrm{i}}\right)$ at this site. $\mathrm{D}$ is the rate of cell division and $f_{\text {main }}^{\mathrm{i}}$ is the efficiency of maintenance methylation at site $i$.

$$
\frac{d \theta_{m}^{i}}{d t}=r_{\text {met }}^{i} *\left(1-\theta_{m}^{i}\right)-\left(\frac{1}{2} D\left(1-f_{\text {main }}^{i}\right)+r_{\text {demeth }}^{i}\right) * \theta_{m}^{i}
$$

According to the authors, Equation (8) has the significant advantage over its predecessor, as it includes the possibility of proofreading/repair mechanisms because of the incorporation of negative feedback. This level of regulation is attained because an increase in methylation causes a reduction in the first term of Equation (8) with a subsequent increase in the second term. Consequently, the methylation rate drops and demethylation increases, resulting in a stable steady-state methylation level at each site. To our knowledge, this theoretical framework has yet to be applied to experimental data or simulated dynamically. A stochastic mathematical framework also inspired Haerter et al. (2014) [80] to create a computational model of this system. Their model differs from the classical/standard model, as it included dynamic collaboration between CpGs. More 


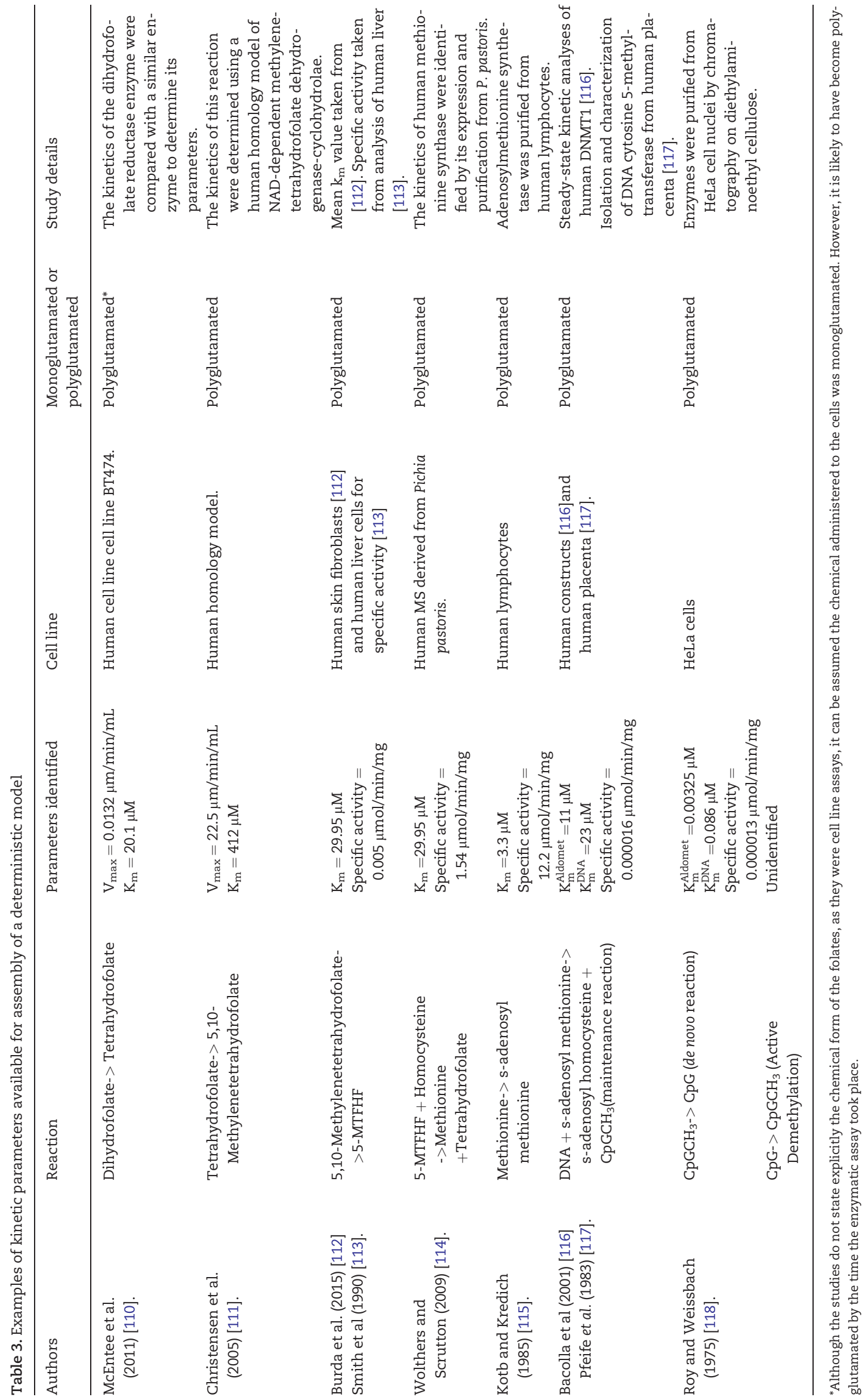




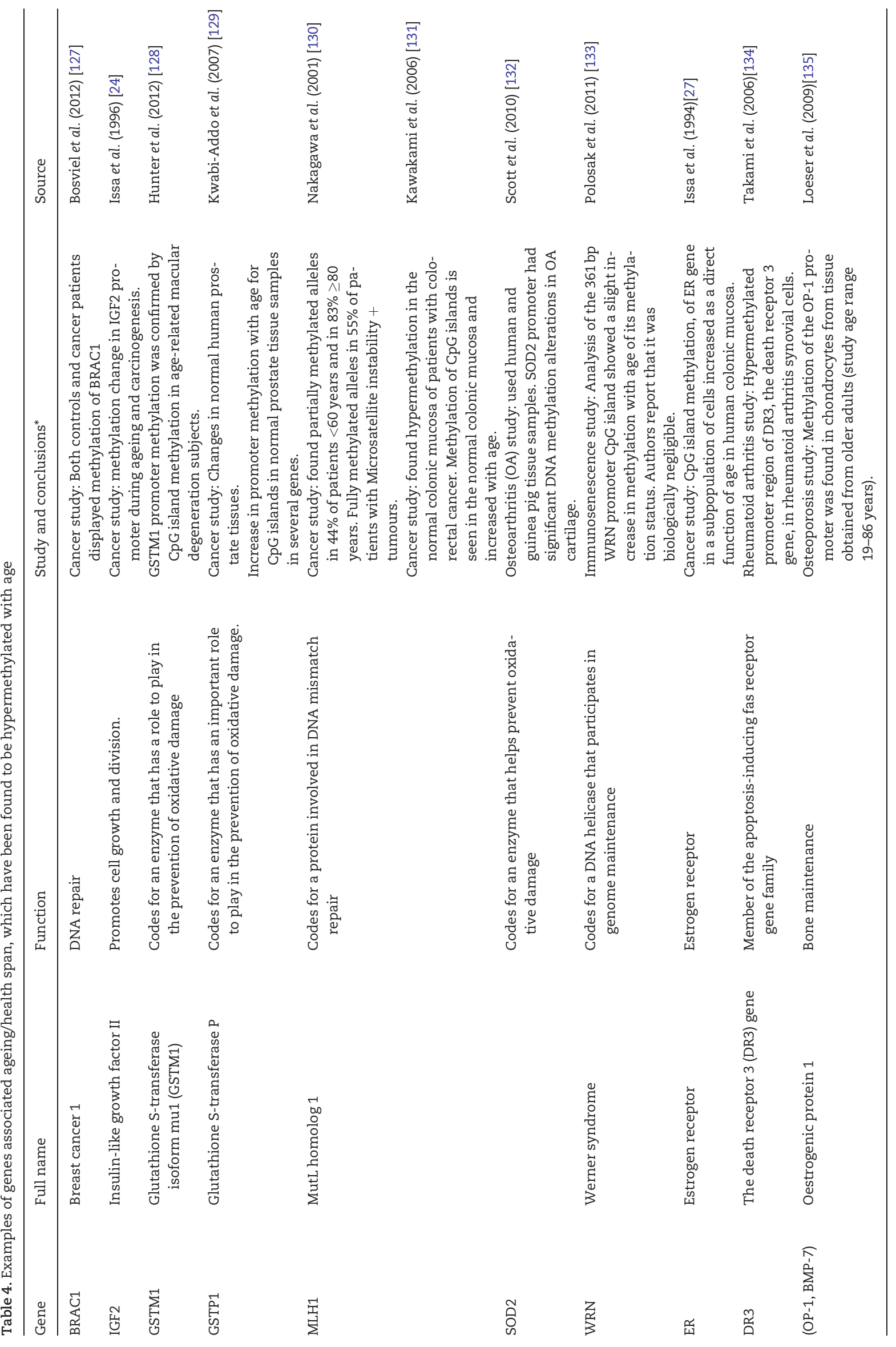


(a) Defining promoter/gene body methylation using intrinsic \& extrinsic noise Cell 1
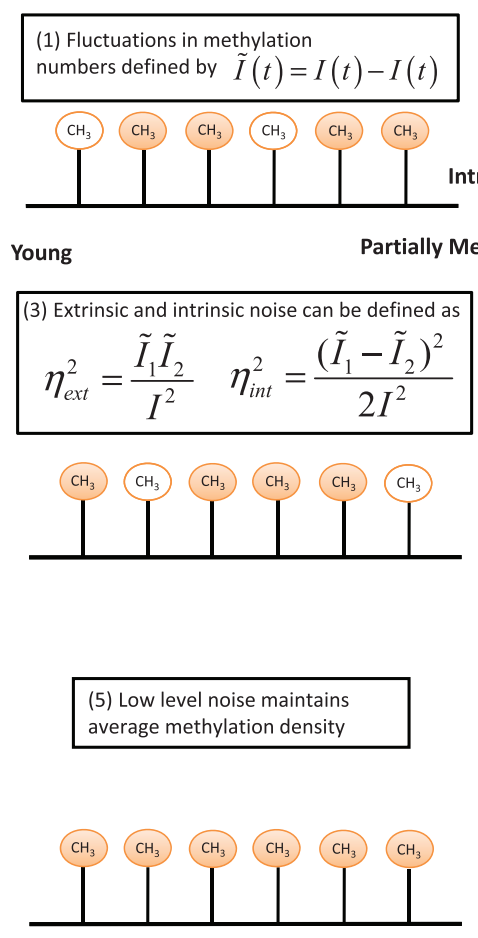

Old

Hypermethylation
Division

\section{Age}

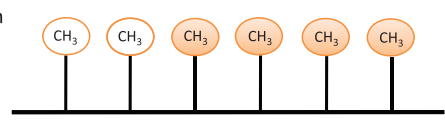

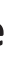

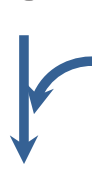

Cell

Division

$$
\frac{\text { (6) Increased noise with age }}{\text { e.g. Folate metabolism }}
$$
e.g. Folate metabolism perturbations

$$
+
$$

factors such as increased oxidative stress
(4) Total noise is defined as

$$
\eta_{\text {int }}^{2}+\eta_{\text {ext }}^{2}=\eta_{\text {tot }}^{2}
$$
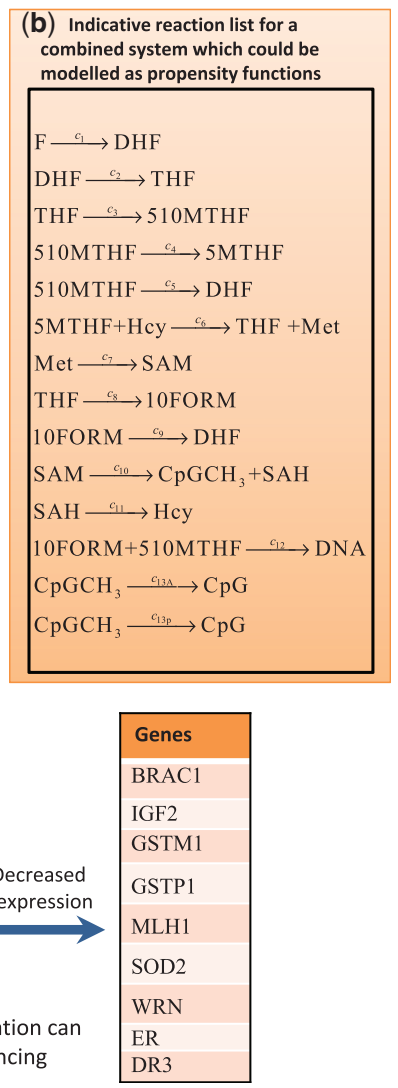

Figure 2. (a) Stochastic contributions to CpG island methylation: Methylation density is affected by intrinsic and extrinsic noise. On the one hand, noise is necessary and evolution has finely tuned this system so that stochasticity helps to maintain average methylation density in young cells. However, the ageing process results in gradual increase in stochasticity, which eventually culminates with promoter hypermethylation. During aging, gene promoter methylation has been identified within a wide variety of genes involved in health span/ageing (refer to Table 4 for full function and description). Included also are the equations, which define intrinsic and extrinsic noise, which are discussed in the main text (mathematical equations based on framework introduced by Elowitz colleagues (2002) [122]). (b) presents a summary of the combined model represented by a set of indicative reactions which could be modelled using propensity functions. Abbreviations: $\mathrm{F}$, folate; THF, tetrahydrofolate; 5MTHF, 5-methyltetrahyrofolate; 510MTHF, 5,10-methylenetetrahydrofolate; Met, methionine; SAM, S-adenosylmethionine; SAH, S-adenosylhomocysteine; Hcy, homocysteine; DHF, dihydrofolate; 10Form, 10-formyl THF.

recently, Olariu et al. (2016) [82] built on the work of Haerter et al. (2014) to model the regulation of transcription and DNA methylation.

\section{Rationale for computationally integrating FOCM and the DNA methylation cycle}

Computational models of FOCM are not fully integrated with the DNA methylation cycle. Rather, as outlined, they have been restricted to the cycle itself or its involvement with DNA synthesis and have tended not to include the DNA methylation cycle. Some have attempted to account for DNA methylation, but no model to our knowledge has explicitly integrated both systems in a meaningful way. We propose computationally integrating FOCM and the methylation cycle. Our biological rationale is unpinned by the knowledge that perturbations in the folate cycle are strongly coupled with aberrant DNA methylation. This is evidenced by the association between low folate status, global DNA hypomethylation and increased cancer risk [87]. In addition, genetic polymorphisms, most notably in the MTHFR gene, which codes for MTHFR, an enzyme that catalyses the conversion of 5, 10-methylenetetrahydrofolate to 5-MTFHF (Figure 1), are associated with gene promoter hypermethylation [88]. Moreover, MS A2756G (MTR A2756G) is a common polymorphism in the gene encoding MS. This enzyme catalyses the regeneration of methionine from Hcy, and disruptions to its enzymatic capabilities also emphasize the close link between folate metabolism and disruptions to DNA methylation. For instance, Weiner and colleagues (2014) [88] found that individuals homozygous for this mutant allele showed higher leukocyte genomic DNA methylation levels than individuals possessing the wild-type genotype (MTR 2756AA). It makes mechanistic sense that perturbations of this nature to FOCM have an impact on DNA methylation, as 5-MTFHF is a cosubstrate for Hcy remethylation to methionine, while MS modulates the dynamics of this reaction, and perturbations to this enzyme result in a rise in plasma Hcy [89], which is associated with CVD [90]. Intriguingly, a rise in plasma Hcy has also been associated with gene promoter hypermethylation [91-94] and global hypomethylation [95-97] of human DNA.

In addition to perturbations because of genetic mutations, it is important to recognize that FOCM compartmentalization could have implications for DNA methylation status, as compartmentalization of FOCM has a role to play in regulating the distribution of one-carbon units within the cell. The partitioning of one-carbon units between nucleotide synthesis and Hcy remethylation is the focal point of this process, where methylenetetrahydrofolate (MTHF) is at the centre of a metabolic 
competition $[98,99]$. On the one hand, MTHF is used as a cofactor during nucleotide synthesis to facilitate the conversion of dUMP to dTMP by thymidylate synthase (TYMS). However, MTHF can also be reduced and is then fully committed to the re-methylation of Hcy. The separation of FOCM into distinct cellular compartments is the determining factor, which regulates the competition between TYMS and MTHFR for MTHF [100]. This regulation requires the trifunctional, enzyme methylenetetrahydrofolate dehydrogenase (MTHFD1), whose activity depends on its cellular location [100]. The interdependence of this enzyme's activity to its location and its involvement in regulating the competition between MTHFR and TYMS are evident when intracellular folate levels are deficient, as insufficient levels of folate cause an accumulation of MTHFD1 in the nucleus, when compared with its cytosolic counterpart [101]. The nuclear build-up of MTHFD1 emphasizes FOCM will sacrifice Hcy remethylation in favour of nucleotide synthesis and underscores the regulatory role compartmentalization plays in one-carbon metabolism. Intriguingly, this aspect of FOCM could have wider implications, as recently it has been shown that changes to MTHFD1 can affect the regulation of DNA methylation. Groth et al. (2016) [102] identified a mutant (mthfd1-1) in Arabidopsis thaliana, which carried a mutation in cytoplasmic MTHFD1. This mutant suffered from accumulation of Hcy and SAM, coupled with extensive genome-wide hypomethylation. Compartmental regulation of FOCM is also highlighted by cytosine serine hydroxymethyltransferase (SHMT). SHMT1 catalyses the conversion of tetrahydrofolate to 5,10 -methylenetetrahydrofolate and also converts serine to glycine. It has been found that cytosine SHMT1 preferentially supplies one-carbon units for thymidylate synthesis [99, 103]. Mechanistically, it has been found that this preference is mediated by small ubiquitin-like modifier (SUMO) modification. This alteration enables the translocation of SHMT to the nucleus and also modifies its catalytic capabilities [104]. Sumoylation could also be crucial to both DNA methylation and demethylation, as SUMO-1 modification of DNMT1 had been shown to significantly enhance DNMT1 activity [105]. It is also possible that sumoylation is capable of modulating the activity of Dnmt3a and Dnmt3b [106]. This level of crossover between FOCM and DNA methylation consolidates the view that disruptions to FOCM impact the dynamics of DNA methylation/demethylation events. However, the full extent of this relationship remains to be elucidated, hence the growing need for an integrated computational model to explore the complex interactions of these systems.

\section{Theoretical frameworks and obstacles to creating a combined model}

To develop a combined model, several theoretical approaches could be adopted. FOCM could be retained as a set of kineticbased ODEs, as is the case in the majority of models of this nature. It would then be straightforward to add the methylation cycle as ODEs also and to define the combined system as a coupled set of ODEs. Despite the obvious computational advantages of this simplification, these benefits are offset by several factors. First, to assemble this deterministic model, the ODEs need to be informed by kinetic data, which account for the behaviour of the methylation enzymes. This is not a straightforward task, as parameter uncertainty is a significant issue in the field of computational systems biology. As outlined, kineticbased models of folate metabolism tend to have rate laws where the velocity of a reaction assumes mass action kinetics or is based on an enzyme kinetic law (e.g. Michaelis-Menten kinetics). Unfortunately, kinetic parameters can vary significantly depending on the circumstances in which their kinetics were quantified and the biological source, with the possibility of model parameters varying by several orders of magnitude depending on the particular source [107]. Therefore, it is extremely unlikely that a mathematical model can be assembled from one biological source. This is highlighted by our recent model of microbial folate metabolism, where the parameters were derived from a number of sources [67]. It is also a feature of the mammalian computational models, which have previously relied on data from rat, mice and human studies [61]. Despite such pitfalls, there is no alternative to this approach of determining model parameters. To this end, a number of databases now exist that archive kinetic data for the purpose of assembling computational models $[108,109]$. We used these databases to identify a series of indicative kinetic parameters for the model outlined diagrammatically in Figure 1 and are summarized in Table 3. The identification of these parameters serves to emphasize that it is possible to assemble a combined kinetic model of folate metabolism and the DNA methylation cycle based on human data; however, the data are limited. Moreover, we were able to identify kinetic parameters for Dnmt1 and Dnmt3A [119, 120]; however, kinetic information for the TET demethylation enzymes could not be identified.

Although, as outlined above, it is clearly possible to assemble a combined deterministic kinetic model, given experimental evidence indicates that DNA methylation events are underscored by stochasticity; a kinetic-based deterministic approach is not the correct way to model this aspect of the system. A more accurate way is to incorporate noise into the model. The standard way of representing noise within biological cells is to describe it mathematically by a master equation or to simulate molecule fluctuations by using a stochastic simulation algorithm (SSA), such as the Gillespie algorithm or one of its derivatives [81, 121]. Routinely embedded within the idea of intracellular noise is the concept of intrinsic versus extrinsic noise, as developed experimentally by Elowitz and colleagues (2002) [122]. Within this context, intrinsic noise refers to the variability inherent to the system under consideration, while fluctuations in those factors classified as external to the system of interest are responsible for extrinsic noise (Figure 2). Specifically, this mathematical approach has been ubiquitously applied to the study of cell-to-cell variability in gene expression levels within isogenic cell populations [123-126].

Applying the above logic to our indicative model, it can be argued that the reactions of the methylation cycle are responsible for generating intrinsic noise, e.g. the inherent statistical mechanical fluctuations in the binding and diffusion dynamics of the molecules involved in maintaining methylation levels within a CpG island/gene body. Conversely, DNA methylation/ the epigenetic state of the cell is considered to be a component of extrinsic noise when variations in gene expression are modelled in this way. We suggest extrinsic noise in our integrated model arises because of biochemical fluctuations originating from the folate cycle and other cell parameters, particularly those related to ageing (Figure 2). Including biochemical noise arising from FOCM is crucial especially if one considers that site-specific (e.g. gene promoter) DNA methylation events interact with FOCM within a microscopic rather than macroscopic environment. This microenvironment is characterized by low molecular populations, which react at discrete time-points, via random collisions between individual molecules. The advantage of this framework is its simplicity, as a complex biological 
network is reduced to a much simpler abstraction. A drawback of this approach is that it reduces the methylation cycle and FOCM to two variables within a phenomenological model, which lumps all sources of extrinsic noise together. Moreover, as we are concerned with the complexities of the reactions of folate metabolism and how changes to these impact DNA methylation events, it is challenging to separate this source of noise from other extrinsic events, e.g. the impact of the cell cycle. A further challenge associated with this proposal is that to characterize the intrinsic noise for a given gene promoter, it would be necessary to experimentally characterize promoterspecific cell-to-cell methylation variability in young diseasefree cells and how this relates to protein expression levels. For instance, microscopy or flow cytometry is routinely used to quantify protein expression variability in reporter genes embedded in homogenous cell populations [136, 137]. Protein count distributions then provide an overview of cell-to-cell fluctuations in gene expression. The stochastic profile can then be characterized as the squared coefficient of variation of the fluorescence levels [138], the coefficient of variation [122] or the Fano factor [139]. Therefore, it would be necessary to develop experimental methods, which are capable of determining the exact nature of the stochasticity of the DNA methylation process. However, given that DNA methylation levels are quantified in a totally different manner to protein fluctuations, it is could be challenging to define/characterize its stochastic signature in a precise way experimentally. Nextgeneration sequencing techniques could help to alleviate this problem. These techniques enable the determination of the methylation status at each cytosine for a specific segment of the genome. An eloquent example of this approach is the work of Hansen et al. (2011) [140], who showed stochastic methylation of cancer-specific DNA-methylated regions. This was able to distinguish cancer from normal tissue. More recently, Cheow et al. (2016) [141] developed a method to genotype individual cells while concurrently probing gene expression and DNA methylation levels at multiple loci. Such methods could help identify an individual stochastic signature for a particular gene promoter/gene body, which would help inform the mathematics underpinning future computational models. An alternative to the reduced stochastic model approach would be to explicitly represent each deterministic kinetic reaction within FOCM and the DNA methylation cycle as stochastic propensity functions and to simulate the integrated model with a SSA [100], as has been done with other complex biochemical systems [142]. In Figure 2B, we have created a list of reactions, which could be represented as propensity functions, where $\mathrm{C}_{1}-$ $C_{7}$ are indicative of stochastic rate constants. This is not unrealistic, as mathematical approaches have been developed previously for converting deterministic systems biology models into stochastic models [143-145]. However, regardless of the approach, it is our opinion that future computational models should combine these two systems together. Moreover, it is imperative that any combined model accounts for the biochemical and molecular variability, which is inherent to both systems. This will improve our overall understanding of how those gene promoters, which appear to be susceptible to hypermethylation, interact with both folate metabolism and the ageing process.

\section{Conclusions}

Folate metabolism and the DNA methylation cycle are inexorably entwined, as the folate cycle provides the methyl groups used in DNA methylation reactions. Experimental evidence suggests the dynamics of the folate cycle and the DNA methylation cycle are subject to inherent stochasticity. Investigating this behaviour is challenging; however, computational modelling offers an ideal framework for exploring the interactions between these two systems. In this review, we proposed building a computational model of folate metabolism coupled with the reactions of the methylation cycle. This model would help to further explore the dynamics of this relationship and could be used to investigate how disruptions to these processes result in aberrant DNA methylation status, specifically gene promoter hypermethylation.

\section{Key Points}

- Folate metabolism has a vital role to play in health and possibly intrinsic ageing.

- Folates supply methyl groups for DNA methylation reactions, which are central to gene regulation.

- Dynamic computational models have been successfully used to study the complexities of folate metabolism and the DNA methylation cycle, respectively, but no model has fully coupled both systems.

- To combine both systems computationally, it is important to account for the inherent stochasticity, which influences the dynamics of both systems.

- Incorporating inherent biochemical and molecular variability will provide an improved understanding of how perturbations to these systems impact the onset of disease and will help to further elucidate the bidirectional relationship between ageing and DNA methylation.

\section{Appendix}

Deterministic model: A model that assumes variability does not impact the system of interest. The model will produce the same output given the same initial conditions and parameters.

Extrinsic noise: Fluctuations in the factors external to the biological system of interest, e.g. biochemical fluctuations in the folate pathway and its impact on gene expression.

Gillespie algorithm: An algorithm used to generate stochastic models of reaction networks.

Intrinsic noise: Noise associated with a biological system of interest, e.g. in the case of this review, site-specific DNA methylation.

Stochastic model: A model grounded in probability theory, which is used to represent the variability inherent in biological processes. In this review, we suggest FOCM is combined with the DNA methylation cycle into a single stochastic model to capture the inherent variability in body systems.

\section{References}

1. Hoffbrand AV, Weir DG. The history of folic acid. $\mathrm{Br} J$ Haematol 2001;113:579-89.

2. Robinson $\mathrm{K}$, Arheart $\mathrm{K}$, Refsum $\mathrm{H}$, et al. Low circulating folate and vitamin $\mathrm{B} 6$ concentrations: risk factors for stroke, peripheral vascular disease, and coronary artery disease. European COMAC Group. Circulation 1998;97:437-43. 
3. Ramos MI, Allen LH, Mungas DM, et al. Low folate status is associated with impaired cognitive function and dementia in the Sacramento Area Latino study on aging. Am J Clin Nutr 2005;82:1346-52.

4. Yakut M, Ustun Y, Kabacam G, et al. Serum vitamin B12 and folate status in patients with inflammatory bowel diseases. Eur J Intern Med 2010;21:320-3.

5. De Bree A, Verschuren WM, Kromhout D, et al. Homocysteine determinants and the evidence to what extent homocysteine determines the risk of coronary heart disease. Pharmacol Rev 2002;54:599-618.

6. Molloy AM. Genetic aspects of folate metabolism. Subcell Biochem 2012;56:105-30.

7. Butterworth CE, Jr. Folate status, women's health, pregnancy outcome, and cancer. J Am Coll Nutr 1993;12:438-41.

8. Piyathilake CJ, Johanning GL, Macaluso M, et al. Localized folate and vitamin B-12 deficiency in squamous cell lung cancer is associated with global DNA hypomethylation. Nutr Cancer 2000;37:99-107.

9. Powers HJ. Interaction among folate, riboflavin, genotype, and cancer, with reference to colorectal and cervical cancer. J Nutr 2005;135:2960s-6s.

10. Chen P, Li C, Li X, et al. Higher dietary folate intake reduces the breast cancer risk: a systematic review and meta-analysis. Br J Cancer 2014;110:2327-38.

11. Corrada MM, Kawas $\mathrm{CH}$, Hallfrisch J, et al. Reduced risk of Alzheimer's disease with high folate intake: the Baltimore longitudinal study of aging. Alzheimers Dement 2005;1:11-8.

12. Patterson D. Folate metabolism and the risk of down syndrome. Downs Syndr Res Pract 2008;12:93-7.

13. Cao Y, Zhang Z, Zheng Y, et al. The association of idiopathic recurrent early pregnancy loss with polymorphisms in folic acid metabolism-related genes. Genes Nutr 2014;9:402.

14. Kelly GS. Folates: supplemental forms and therapeutic applications. Altern Med Rev 1998;3:208-20.

15. Crider KS, Yang TP, Berry RJ, et al. Folate and DNA methylation: a review of molecular mechanisms and the evidence for folate's role. Adv Nutr 2012;3:21-38.

16. Li E, Zhang Y. DNA methylation in mammals. Cold Spring Harb Perspect Biol 2014;6:a019133.

17. Messerschmidt DM, Knowles BB, Solter D. DNA methylation dynamics during epigenetic reprogramming in the germline and preimplantation embryos. Genes Dev 2014;28:812-28.

18. Feil R. Epigenetics, an emerging discipline with broad implications. C R Biol 2008;331:837-43.

19. Jaenisch R, Bird A. Epigenetic regulation of gene expression: how the genome integrates intrinsic and environmental signals. Nat Genet 2003;33(Suppl):245-54.

20. Richardson BC. Role of DNA methylation in the regulation of cell function: autoimmunity, aging and cancer. $J$ Nutr 2002;132:2401S-5S.

21. Wilson VL, Smith RA, Ma S, et al. Genomic 5-methyldeoxycytidine decreases with age. J Biol Chem 1987;262:9948-51.

22. Fuke C, Shimabukuro M, Petronis A, et al. Age related changes in 5-methylcytosine content in human peripheral leukocytes and placentas: an HPLC-based study. Ann Hum Genet 2004;68:196-204.

23. Wilson VL, Jones PA. DNA methylation decreases in aging but not in immortal cells. Science 1983;220:1055-7.

24. Issa JP, Vertino PM, Boehm CD, et al. Switch from monoallelic to biallelic human IGF2 promoter methylation during aging and carcinogenesis. Proc Natl Acad Sci USA 1996;93:11757-62.

25. Esteller M, Corn PG, Baylin SB, et al. A gene hypermethylation profile of human cancer. Cancer Res 2001;61:3225-9.
26. Maegawa S, Hinkal G, Kim HS, et al. Widespread and tissue specific age-related DNA methylation changes in mice. Genome Res 2010;20:332-40.

27. Issa JP, Ottaviano YL, Celano P, et al. Methylation of the oestrogen receptor CpG island links ageing and neoplasia in human colon. Nat Genet 1994;7:536-40.

28. Dong SM, Kim HS, Rha SH, et al. Promoter hypermethylation of multiple genes in carcinoma of the uterine cervix. Clin Cancer Res 2001;7:1982-6.

29. Harden SV, Tokumaru Y, Westra WH, et al. Gene promoter hypermethylation in tumors and lymph nodes of stage I lung cancer patients. Clin Cancer Res 2003;9:1370-5.

30. Kane MF, Loda M, Gaida GM, et al. Methylation of the hMLH1 promoter correlates with lack of expression of hMLH1 in sporadic colon tumors and mismatch repair-defective human tumor cell lines. Cancer Res 1997;57:808-11.

31. Esteller M, Silva JM, Dominguez G, et al. Promoter hypermethylation and BRCA1 inactivation in sporadic breast and ovarian tumors. J Natl Cancer Inst 2000;92:564-9.

32. Wang Y, Zhang J, Xiao X, et al. The identification of ageassociated cancer markers by an integrative analysis of dynamic DNA methylation changes. Sci Rep 2016;6:22722.

33. Abi Khalil C. The emerging role of epigenetics in cardiovascular disease. Ther Adv Chronic Dis 2014;5:178-87.

34. De Jager PL, Srivastava G, Lunnon K, et al. Alzheimer's disease: early alterations in brain DNA methylation at ANK1, BIN1, RHBDF2 and other loci. Nat Neurosci 2014;17:1156-63.

35. Delgado-Calle J, Fernandez AF, Sainz J, et al. Genome-wide profiling of bone reveals differentially methylated regions in osteoporosis and osteoarthritis. Arthritis Rheum 2013;65: 197-205.

36. Horvath S. DNA methylation age of human tissues and cell types. Genome Biol 2013;14:R115.

37. Ulrey CL, Liu L, Andrews LG, et al. The impact of metabolism on DNA methylation. Hum Mol Genet 2005;14:R139-47.

38. Muratore CR, Hodgson NW, Trivedi MS, et al. Age-dependent decrease and alternative splicing of methionine synthase mRNA in human cerebral cortex and an accelerated decrease in autism. PLoS One 2013;8:e56927.

39. Spotila LD, Jacques PF, Berger PB, et al. Age dependence of the influence of methylenetetrahydrofolate reductase genotype on plasma homocysteine level. Am J Epidemiol 2003;158:871-7.

40. Li Y, Liu Y, Strickland FM, et al. Age-dependent decreases in DNA methyltransferase levels and low transmethylation micronutrient levels synergize to promote overexpression of genes implicated in autoimmunity and acute coronary syndromes. Exp Gerontol 2010;45:312-22.

41. Zhang Y, Hodgson NW, Trivedi MS, et al. Decreased brain levels of Vitamin B12 in aging, autism and schizophrenia. PLoS One 2016;11:e0146797.

42. Franco R, Schoneveld O, Georgakilas AG, et al. Oxidative stress, DNA methylation and carcinogenesis. Cancer Lett 2008;266:6-11.

43. Hondorp ER, Matthews RG. Oxidative stress inactivates cobalamin-independent methionine synthase (MetE) in Escherichia coli. PLoS Biol 2004;2:e336.

44. Haller J. The vitamin status and its adequacy in the elderly: an international overview. Int J Vitam Nutr Res 1999;69:160-8.

45. Mooney KM, Morgan AE, Mc Auley MT. Aging and computational systems biology. Wiley Interdiscip Rev Syst Biol Med 2016;8:123-39.

46. Mc Auley MT, Choi H, Mooney K, et al. Systems biology and synthetic biology: a new epoch for toxicology research. Adv Toxicol 2015;2015:14. 
47. Mc Auley MT, Mooney KM. Computational systems biology for aging research. Interdiscip Top Gerontol 2015;40:35-48.

48. Mc Auley MT, Mooney KM. Computationally modeling lipid metabolism and aging: a mini-review. Comput Struct Biotechnol J 2015;13:38-46.

49. Mc Auley MT, Mooney KM, Angell PJ, et al. Mathematical modelling of metabolic regulation in aging. Metabolites 2015; 5(2):232-51.

50. Mc Auley MT, Proctor CJ, Corfe BM, et al. Nutrition research and the impact of computational systems biology. J Comput Sci Syst Biol 2013;6:271-85.

51. Robertson KD. DNA methylation, methyltransferases, and cancer. Oncogene 2001;20:3139-55.

52. Arasaradnam RP, Commane DM, Bradburn D, et al. A review of dietary factors and its influence on DNA methylation in colorectal carcinogenesis. Epigenetics 2008;3:193-8.

53. Bailey LB, Gregory JF. 3rd. Folate metabolism and requirements. J Nutr 1999;129:779-82.

54. Robertson KD, Uzvolgyi E, Liang G, et al. The human DNA methyltransferases (DNMTs) 1, 3a and 3b: coordinate mRNA expression in normal tissues and overexpression in tumors. Nucleic Acids Res 1999;27:2291-8.

55. Chen T, Ueda Y, Dodge JE, et al. Establishment and maintenance of genomic methylation patterns in mouse embryonic stem cells by Dnmt3a and Dnmt3b. Mol Cell Biol 2003;23: 5594-605.

56. Okano M, Bell DW, Haber DA, et al. DNA methyltransferases Dnmt3a and Dnmt3b are essential for de novo methylation and mammalian development. Cell 1999;99:247-57.

57. Scourzic L, Mouly E, Bernard OA. TET proteins and the control of cytosine demethylation in cancer. Genome Med 2015;7:9.

58. Landan G, Cohen NM, Mukamel Z, et al. Epigenetic polymorphism and the stochastic formation of differentially methylated regions in normal and cancerous tissues. Nat Genet 2012;44:1207-14.

59. Shipony Z, Mukamel Z, Cohen NM, et al. Dynamic and static maintenance of epigenetic memory in pluripotent and somatic cells. Nature 2014;513:115-9.

60. Jackson RC, Harrap KR. Studies with a mathematical model of folate metabolism. Arch Biochem Biophys 1973;158:827-41.

61. Nijhout HF, Reed MC, Budu P, et al. A mathematical model of the folate cycle: new insights into folate homeostasis. J Biol Chem 2004;279:55008-16.

62. Reed MC, Nijhout HF, Neuhouser ML, et al. A mathematical model gives insights into nutritional and genetic aspects of folate-mediated one-carbon metabolism. J Nutr 2006;136: 2653-61.

63. Reed MC, Nijhout HF, Sparks R, et al. A mathematical model of the methionine cycle. J Theor Biol 2004;226:33-43.

64. Nijhout HF, Reed MC, Anderson DF, et al. Long-range allosteric interactions between the folate and methionine cycles stabilize DNA methylation reaction rate. Epigenetics 2006;1: 81-7.

65. Neuhouser ML, Nijhout HF, Gregory JF, 3rd, et al. Mathematical modeling predicts the effect of folate deficiency and excess on cancer-related biomarkers. Cancer Epidemiol Biomarkers Prev 2011;20:1912-7.

66. Duncan TM, Reed MC, Nijhout HF. A population model of folate-mediated one-carbon metabolism. Nutrients 2013;5: 2457-74.

67. Enrique Salcedo-Sora J, Mc Auley MT. A mathematical model of microbial folate biosynthesis and utilisation: implications for antifolate development. Mol Biosyst 2016;12: 923-33.
68. Capra JA, Kostka D. Modeling DNA methylation dynamics with approaches from phylogenetics. Bioinformatics 2014;30: i408-14.

69. Genereux DP, Miner BE, Bergstrom CT, et al. A populationepigenetic model to infer site-specific methylation rates from double-stranded DNA methylation patterns. Proc Natl Acad Sci USA 2005;102:5802-7.

70. Flottmann M, Scharp T, Klipp E. A stochastic model of epigenetic dynamics in somatic cell reprogramming. Front Physiol 2012;3:216.

71. Zheng $\mathrm{H}, \mathrm{Wu} \mathrm{H}$, Li J, et al. CpGIMethPred: computational model for predicting methylation status of CPG islands in human genome. BMC Med Genomics 2013;6(Suppl 1):S13.

72. Feinberg AP, Irizarry RA. Evolution in health and medicine Sackler colloquium: stochastic epigenetic variation as a driving force of development, evolutionary adaptation, and disease. Proc Natl Acad Sci USA 2010;107(Suppl 1):1757-64.

73. Przybilla J, Rohlf T, Loeffler M, et al. Understanding epigenetic changes in aging stem cells-a computational model approach. Aging Cell 2014;13:320-8.

74. Sontag LB, Lorincz MC, Georg Luebeck E. Dynamics, stability and inheritance of somatic DNA methylation imprints. J Theor Biol 2006;242:890-9.

75. Ro S, Rannala B. Methylation patterns and mathematical models reveal dynamics of stem cell turnover in the human colon. Proc Natl Acad Sci USA 2001;98:10519-21.

76. Otto SP, Walbot V. DNA methylation in eukaryotes: kinetics of demethylation and de novo methylation during the life cycle. Genetics 1990;124:429-37.

77. McGovern AP, Powell BE, Chevassut TJ. A dynamic multicompartmental model of DNA methylation with demonstrable predictive value in hematological malignancies. J Theor Biol 2012;310:14-20.

78. Riggs AD, Xiong Z. Methylation and epigenetic fidelity. Proc Natl Acad Sci USA 2004;101:4-5.

79. Jeltsch A, Jurkowska RZ. New concepts in DNA methylation. Trends Biochem Sci 2014;39:310-8.

80. Haerter JO, Lovkvist C, Dodd IB, et al. Collaboration between CPG sites is needed for stable somatic inheritance of DNA methylation states. Nucleic Acids Res 2014;42:2235-44.

81. Gillespie D. A general method for numerically simulating stochastic time evolution of coupled chemical-reactions. J Comput Phys 1976;22:403-34.

82. Olariu V, Lovkvist C, Sneppen K. Nanog, Oct4 and Tet1 interplay in establishing pluripotency. Sci Rep 2016;6:25438.

83. Nijhout HF, Reed MC, Ulrich CM. Mathematical models of folate-mediated one-carbon metabolism. Vitam Horm 2008; 79:45-82.

84. Voit EO, Martens HA, Omholt SW. 150 years of the mass action law. PLoS Comput Biol 2015;11:e1004012.

85. Michaelis L, Menten ML, Johnson KA, et al. The original Michaelis constant: translation of the 1913 MichaelisMenten paper. Biochemistry 2011;50:8264-9.

86. Pfeifer GP, Steigerwald SD, Hansen RS, et al. Polymerase chain reaction-aided genomic sequencing of an $\mathrm{X}$ chromosome-linked CpG island: methylation patterns suggest clonal inheritance, CpG site autonomy, and an explanation of activity state stability. Proc Natl Acad Sci USA 1990;87:8252-6.

87. Pufulete M, Al-Ghnaniem R, Leather AJ, et al. Folate status, genomic DNA hypomethylation, and risk of colorectal adenoma and cancer: a case control study. Gastroenterology 2003;124:1240-8. 
88. Weiner AS, Boyarskikh UA, Voronina EN, et al. Methylenetetrahydrofolate reductase C677T and methionine synthase A2756G polymorphisms influence on leukocyte genomic DNA methylation level. Gene 2014;533: 168-72.

89. Harmon DL, Shields DC, Woodside JV, et al. Methionine synthase D919G polymorphism is a significant but modest determinant of circulating homocysteine concentrations. Genet Epidemiol 1999;17:298-309.

90. Ganguly P, Alam SF. Role of homocysteine in the development of cardiovascular disease. Nutr J 2015;14:6.

91. Zhang JG, Liu JX, Li ZH, et al. Dysfunction of endothelial NO system originated from homocysteine-induced aberrant methylation pattern in promoter region of DDAH2 gene. Chin Med J 2007;120:2132-7.

92. Bonsch D, Lenz B, Reulbach U, et al. Homocysteine associated genomic DNA hypermethylation in patients with chronic alcoholism. J Neural Transm 2004;111:1611-6.

93. Zhi Y, Huang Y, Li Z, et al. Hypermethylation of estrogen receptor-alpha gene and high homocysteine in atheromatosis patients, (in Chinese). Wei Sheng Yan Jiu 2008;37:314-7.

94. Huang Y, Peng K, Su J, et al. Different effects of homocysteine and oxidized low density lipoprotein on methylation status in the promoter region of the estrogen receptor alpha gene. Acta Biochim Biophys Sin 2007;39:19-26.

95. Lee ME, Wang H. Homocysteine and hypomethylation. A novel link to vascular disease. Trends Cardiovasc Med 1999;9:49-54.

96. Yi P, Melnyk S, Pogribna $\mathrm{M}$, et al. Increase in plasma homocysteine associated with parallel increases in plasma S-adenosylhomocysteine and lymphocyte DNA hypomethylation. J Biol Chem 2000;275:29318-23.

97. Zhang D, Sun X, Liu J, et al. Homocysteine accelerates senescence of endothelial cells via DNA hypomethylation of human telomerase reverse transcriptase. Arterioscler Thromb Vasc Biol 2015;35:71-8.

98. MacFarlane AJ, Liu X, Perry CA, et al. Cytoplasmic serine hydroxymethyltransferase regulates the metabolic partitioning of methylenetetrahydrofolate but is not essential in mice. J Biol Chem 2008;283:25846-53.

99. Herbig K, Chiang EP, Lee LR, et al. Cytoplasmic serine hydroxymethyltransferase mediates competition between folatedependent deoxyribonucleotide and S-adenosylmethionine biosyntheses. J Biol Chem 2002;277:38381-9.

100. Scotti M, Stella L, Shearer EJ, et al. Modeling cellular compartmentation in one-carbon metabolism. Wiley Interdiscip Rev Syst Biol Med 2013;5:343-65.

101. Field MS, Kamynina E, Agunloye OC, et al. Nuclear enrichment of folate cofactors and methylenetetrahydrofolate dehydrogenase 1 (MTHFD1) protect de novo thymidylate biosynthesis during folate deficiency. J Biol Chem 2014;289: 29642-50.

102. Groth M, Moissiard G, Wirtz M. MTHFD1 controls DNA methylation in Arabidopsis. 2016;7:11640.

103. Anderson DD, Woeller CF, Chiang EP, et al. Serine hydroxymethyltransferase anchors de novo thymidylate synthesis pathway to nuclear lamina for DNA synthesis. J Biol Chem 2012;287:7051-62.

104. Anderson DD, Eom JY, Stover PJ. Competition between sumoylation and ubiquitination of serine hydroxymethyltransferase 1 determines its nuclear localization and its accumulation in the nucleus. J Biol Chem 2012;287:4790-9.

105. Lee B, Muller MT. SUMOylation enhances DNA methyltransferase 1 activity. Biochem J 2009;421:449-61.
106. Ling Y, Sankpal UT, Robertson AK, et al. Modification of de novo DNA methyltransferase 3a (Dnmt3a) by SUMO-1 modulates its interaction with histone deacetylases (HDACs) and its capacity to repress transcription. Nucleic Acids Res 2004;32:598-610.

107. Gutenkunst RN, Waterfall JJ, Casey FP, et al. Universally sloppy parameter sensitivities in systems biology models. PLoS Comput Biol 2007;3:1871-8.

108. Scheer M, Grote A, Chang A, et al. BRENDA, the enzyme information system in 2011. Nucleic Acids Res 2011;39:D670-6.

109. Wittig U, Kania R, Golebiewski M, et al. SABIO-RK-database for biochemical reaction kinetics. Nucleic Acids Res 2012; 40:D790-6.

110. McEntee G, Minguzzi S, O'Brien K, et al. The former annotated human pseudogene dihydrofolate reductase-like 1 (DHFRL1) is expressed and functional. Proc Natl Acad Sci USA 2011;108:15157-62.

111. Christensen KE, Mirza IA, Berghuis AM, et al. Magnesium and phosphate ions enable NAD binding to methylenetetrahydrofolate dehydrogenase-methenyltetrahydrofolate cyclohydrolase. J Biol Chem 2005;280:34316-23.

112. Burda P, Schafer A, Suormala T, et al. Insights into severe 5,10-methylenetetrahydrofolate reductase deficiency: molecular genetic and enzymatic characterization of 76 patients. Hum Mutat 2015;36:611-21.

113. Smith GK, Banks SD, Monaco TJ, et al. Activity of an NADdependent 5,10-methylenetetrahydrofolate dehydrogenase in normal tissue, neoplastic cells, and oncogenetransformed cells. Arch Biochem Biophys 1990;283:367-71.

114. Wolthers KR, Scrutton NS. Cobalamin uptake and reactivation occurs through specific protein interactions in the methionine synthase-methionine synthase reductase complex. Febs J 2009;276:1942-51.

115. Kotb M, Kredich NM. S-Adenosylmethionine synthetase from human lymphocytes. Purification and characterization. J Biol Chem 1985;260:3923-30.

116. Bacolla A, Pradhan S, Larson JE, et al. Recombinant human DNA (cytosine-5) methyltransferase. III. Allosteric control, reaction order, and influence of plasmid topology and triplet repeat length on methylation of the fragile X CGG.CCG sequence. J Biol Chem 2001;276:18605-13.

117. Pfeifer GP, Grunwald S, Boehm TL, et al. Isolation and characterization of DNA cytosine 5-methyltransferase from human placenta. Biochim Biophys Acta 1983;740:323-30.

118. Roy PH, Weissbach A. DNA methylase from HeLa cell nuclei. Nucleic Acids Res 1975;2:1669-84.

119. Pradhan M, Esteve PO, Chin HG, et al. CXXC domain of human DNMT1 is essential for enzymatic activity. Biochemistry 2008;47:10000-9.

120. Balada E, Ordi-Ros J, Serrano-Acedo S, et al. Transcript levels of DNA methyltransferases DNMT1, DNMT3A and DNMT3B in CD4+ T cells from patients with systemic lupus erythematosus. Immunology 2008;124:339-47.

121. Gibson MA, Bruck J. Efficient exact stochastic simulation of chemical systems with many species and many channels. J Phys Chem 2000;A 104:1876-89.

122. Elowitz MB, Levine AJ, Siggia ED, et al. Stochastic gene expression in a single cell. Science 2002;297:1183-6.

123. Singh A, Soltani M. Quantifying intrinsic and extrinsic variability in stochastic gene expression models. PLoS One 2013;8:e84301.

124. Raser JM, O'Shea EK. Control of stochasticity in eukaryotic gene expression. Science 2004;304:1811-4. 
125. Raj A, van Oudenaarden A. Nature, nurture, or chance: stochastic gene expression and its consequences. Cell 2008; 135:216-26.

126. Wilkinson DJ. Stochastic modelling for quantitative description of heterogeneous biological systems. Nat Rev Genet 2009;10:122-33.

127. Bosviel R, Garcia S, Lavediaux G, et al. BRCA1 promoter methylation in peripheral blood DNA was identified in sporadic breast cancer and controls. Cancer Epidemiol 2012;36: e177-82.

128. Hunter A, Spechler PA, Cwanger A, et al. DNA methylation is associated with altered gene expression in AMD. Invest Ophthalmol Vis Sci 2012;53:2089-105.

129. Kwabi-Addo B, Chung W, Shen L, et al. Age-related DNA methylation changes in normal human prostate tissues. Clin Cancer Res 2007;13:3796-802.

130. Nakagawa H, Nuovo GJ, Zervos EE, et al. Age-related hypermethylation of the 5' region of MLH1 in normal colonic mucosa is associated with microsatellite-unstable colorectal cancer development. Cancer Res 2001;61:6991-5.

131. Kawakami K, Ruszkiewicz A, Bennett G, et al. DNA hypermethylation in the normal colonic mucosa of patients with colorectal cancer. Br J Cancer 2006;94:593-8.

132. Scott JL, Gabrielides C, Davidson RK, et al. Superoxide dismutase downregulation in osteoarthritis progression and endstage disease. Ann Rheum Dis 2010;69:1502-10.

133. Polosak J, Kurylowicz A, Roszkowska-Gancarz M, et al. Aging is accompanied by a progressive decrease of expression of the WRN gene in human blood mononuclear cells. J Gerontol a Biol Sci Med Sci 2011;66:19-25.

134. Takami N, Osawa K, Miura Y, et al. Hypermethylated promoter region of DR3, the death receptor 3 gene, in rheumatoid arthritis synovial cells. Arthritis Rheum 2006;54:779-87.
135. Loeser RF, Im HJ, Richardson B, et al. Methylation of the OP-1 promoter: potential role in the age-related decline in OP-1 expression in cartilage. Osteoarthritis Cartilage 2009;17:513-7.

136. Wei T, Dai H. Quantification of GFP signals by fluorescent microscopy and flow cytometry. Methods Mol Biol 2014;1163: 23-31.

137. Soboleski MR, Oaks J, Halford WP. Green fluorescent protein is a quantitative reporter of gene expression in individual eukaryotic cells. Faseb J 2005;19:440-2.

138. Sigal A, Milo R, Cohen A, et al. Variability and memory of protein levels in human cells. Nature 2006;444:643-6.

139. Thattai M, van Oudenaarden A. Intrinsic noise in gene regulatory networks. Proc Natl Acad Sci USA 2001;98:8614-9.

140. Hansen KD, Timp W, Bravo HC, et al. Increased methylation variation in epigenetic domains across cancer types. Nat Genet 2011;43:768-75.

141. Cheow LF, Courtois ET, Tan Y, et al. Single-cell multimodal profiling reveals cellular epigenetic heterogeneity. Nat Methods 2016;13, 833-6.

142. Proctor CJ, Gray DA. Explaining oscillations and variability in the p53-Mdm2 system. BMC Syst Biol 2008;2:75.

143. Wu J, Vidakovic B, Voit EO. Constructing stochastic models from deterministic process equations by propensity adjustment. BMC Syst Biol 2011;5:187.

144. Ball DA, Ahn TH, Wang P, et al. Stochastic exit from mitosis in budding yeast: model predictions and experimental observations. Cell Cycle 2011;10:999-1009.

145. Puchalka J, Kierzek AM. Bridging the gap between stochastic and deterministic regimes in the kinetic simulations of the biochemical reaction networks. Biophys J 2004;86: 1357-72. 